Published in final edited form as:

Respir Physiol Neurobiol. 2008 February 29; 160(3): 301-312.

\title{
Respiratory plasticity after perinatal hyperoxia is not prevented by antioxidant supplementation
}

\author{
Ryan W. Bavis ${ }^{a}{ }^{*}$, Julie M. Wenninger ${ }^{b}$, Brooke M. Millera ${ }^{a}$ Elizabeth F. Dmitrieffa, E. Burt \\ Olson Jr. ${ }^{\mathrm{C}}$, Gordon S. Mitchell ${ }^{\mathrm{b}}$, and Gerald E. Bisgard ${ }^{\mathrm{b}}$ \\ aDepartment of Biology, Bates College, Lewiston, ME 04240 USA \\ bDepartment of Comparative Biosciences, University of Wisconsin, Madison, WI 53706 USA \\ cDepartment of Population Health Sciences, University of Wisconsin, Madison, WI 53706 USA
}

\begin{abstract}
Perinatal hyperoxia attenuates the hypoxic ventilatory response in rats by altering development of the carotid body and its chemoafferent neurons. In this study, we tested the hypothesis that hyperoxia elicits this maladaptive plasticity through the increased production of reactive oxygen species (ROS). Rats were born and raised in $60 \% \mathrm{O}_{2}$ for the first two postnatal weeks while treated with one of two antioxidants: vitamin E (via milk from mothers whose diet was enriched with $1000 \mathrm{IU}$ vitamin $\mathrm{E}$ $\mathrm{kg}^{-1}$ ) or a superoxide dismutase mimetic, manganese (III) tetrakis (1-methyl-4-pyridyl) porphyrin pentachloride (MnTMPyP; via daily intraperitoneal injection of 5-10 mg kg-1 ); rats were subsequently raised in room air until studied as adults. Peripheral chemoreflexes, assessed by carotid sinus nerve responses to cyanide, asphyxia, anoxia and isocapnic hypoxia (vitamin E experiments) or by hypoxic ventilatory responses (MnTMPyP experiments), were reduced after perinatal hyperoxia compared to those of normoxia-reared controls (all $P<0.01$ ); antioxidant treatment had no effect on these responses. Similarly, the carotid bodies of hyperoxia-reared rats were only one-third the volume of carotid bodies from normoxia-reared controls $(P<0.001)$, regardless of antioxidant treatment. Protein carbonyl concentrations in the blood plasma, measured as an indicator of oxidative stress, were not increased in neonatal rats ( 2 and 8 days of age) exposed to $60 \% \mathrm{O}_{2}$ from birth. Collectively, these data do not support the hypothesis that perinatal hyperoxia impairs peripheral chemoreceptor development through ROS-mediated oxygen toxicity.
\end{abstract}

\section{Introduction}

Chronic exposure to hyperoxia $\left(30-60 \% \mathrm{O}_{2}\right.$ ) during postnatal development attenuates the hypoxic ventilatory response (HVR) in adult rats (Ling et al., 1997; Bavis, 2005). Persistent changes in the HVR reflect abnormal development of the carotid body and its afferent neurons. Rats reared in hyperoxia exhibit persistent carotid body hypoplasia and have fewer chemoafferent neurons in the carotid sinus nerve (CSN) and petrosal ganglion (Erickson et al., 1998; Bisgard et al., 2003; Prieto-Lloret et al., 2004). Moreover, many of the remaining $\mathrm{O}_{2}$ sensitive glomus cells and chemoafferent neurons fail to respond to hypoxia or exhibit abnormal responses (Prieto-Lloret et al., 2004; Donnelly et al., 2005). As a result, whole-nerve

*Corresponding author: Ryan W. Bavis, PhD, Department of Biology, Bates College, 44 Campus Ave., Carnegie Science Hall, Lewiston, ME 04240 USA, Phone: 207-786-8269, Fax: 207-786-8334, Email: rbavis@bates.edu.

Publisher's Disclaimer: This is a PDF file of an unedited manuscript that has been accepted for publication. As a service to our customers we are providing this early version of the manuscript. The manuscript will undergo copyediting, typesetting, and review of the resulting proof before it is published in its final citable form. Please note that during the production process errors may be discovered which could affect the content, and all legal disclaimers that apply to the journal pertain. 
CSN responses to hypoxia are greatly reduced throughout life (Ling et al., 1997; Fuller et al., 2002; Bisgard et al., 2003).

The mechanisms by which hyperoxia alters morphological and functional development of the carotid body and its chemoafferent neurons are not yet known. It has been proposed that hyperoxia inhibits peripheral chemoreceptors, thereby disrupting normal, activity-dependent development of the carotid body and its chemoafferent pathway (Ling et al., 1997; Bavis et al., 2007). Alternatively, the observed changes in the carotid body could be the result of $\mathrm{O}_{2}$ toxicity. Hyperoxia increases the production of toxic reactive oxygen species (ROS), notably the superoxide anion $\left(\mathrm{O}_{2}^{--}\right)$, which in turn may produce other oxidizing agents such as hydrogen peroxide $\left(\mathrm{H}_{2} \mathrm{O}_{2}\right)$ (Jamieson et al., 1986). When ROS production outpaces the body's antioxidant defenses, ROS may damage proteins, DNA and biological membranes, thus impairing cellular function, initiating cell death (necrosis or apoptosis) and preventing cell proliferation (Jamieson et al., 1986; O'Reilly, 2001). Indeed, several studies have identified morphological and functional changes in the carotid body consistent with $\mathrm{O}_{2}$ toxicity after chronically exposing adult cats and rats to normobaric hyperoxia (98-100\% $\mathrm{O}_{2}$; Lahiri et al., 1987; Mokashi and Lahiri, 1991; Mokashi et al., 1994; Di Giulio et al., 1998). Moreover, exposure of chemoafferent neurons in the petrosal ganglion to hyperoxia in vitro increases ROS production, cell damage and cell death (Kwak et al., 2006); these effects can be blocked with antioxidants. Thus, excessive ROS production could potentially explain the reduced carotid body volume, loss of afferent neurons and/or impaired $\mathrm{O}_{2}$ transduction observed after perinatal hyperoxia.

On the other hand, it is not clear that the levels of hyperoxia $\left(30-60 \% \mathrm{O}_{2}\right)$ or the duration of hyperoxic exposures (1-2 weeks) used to elicit respiratory plasticity are sufficient to cause significant $\mathrm{O}_{2}$ toxicity in vivo (Erickson et al., 1998; Bavis et al., 2002, 2003; Bisgard et al., 2003). Studies suggesting overproduction of ROS and/or $\mathrm{O}_{2}$ toxicity at the level of the carotid body or chemoafferent neurons have employed severe normobaric hyperoxia in vivo (98-100\% $\mathrm{O}_{2}$; Lahiri et al., 1987; Mokashi and Lahiri, 1991; Mokashi et al., 1994; Di Giulio et al., $1998)$ or in vitro $\left(95 \% \mathrm{O}_{2}\right.$; Kwak et al., 2006). Chronic exposure to only $40-65 \% \mathrm{O}_{2}$ for $1-4$ weeks can induce pulmonary pathology in neonatal rats and mice (Bucher and Roberts, 1981; Ling et al., 1996; Dauger et al., 2003), but lungs and airways are particularly susceptible to hyperoxia since they experience much higher of $\mathrm{O}_{2}$ partial pressures $\left(\mathrm{P}_{\mathrm{O}_{2}}\right)$ than systemic tissues; tissue $\mathrm{P}_{\mathrm{O}_{2}}$ away from the lungs increases very little during normobaric hyperoxia (e.g., mixed venous $\mathrm{P}_{\mathrm{O}_{2}}$ typically increases $<10 \mathrm{mmHg}$ while breathing $100 \% \mathrm{O}_{2}$; Lumb, 2005). Indeed, the effects of perinatal exposure to $60 \% \mathrm{O}_{2}$ are confined to the carotid chemoafferent pathway, with no apparent morphological changes in other neural pathways (Erickson et al., 1998; Prieto-Lloret et al., 2004), or functional changes in the hypercapnic ventilatory response or CNS integration of chemoafferent inputs (Ling et al., 1997; Fuller et al., 2002; Prieto-Lloret et al., 2004) that might be expected if systemic $\mathrm{O}_{2}$ toxicity had occurred. Although the carotid body may experience more ROS production than many other tissues owing to its relatively high blood flow (Mokashi and Lahiri, 1991), one-month exposures to $60 \% \mathrm{O}_{2}$ have no persistent effect on the HVR of rats exposed as adults (Ling et al., 1996, 1997). It is possible, therefore, that upregulation of the body's natural antioxidant defenses effectively prevents $\mathrm{O}_{2}$ toxicity during exposures to moderate hyperoxia (Lee et al., 2005).

In the present study, we tested the hypothesis that excessive ROS contribute to abnormal development of hypoxic ventilatory responses in rats exposed to perinatal hyperoxia. Our first approach was to determine whether antioxidant supplementation would prevent the effects of hyperoxia on carotid body morphology and hypoxic responses. We selected two antioxidants for these experiments, vitamin E ( $\alpha$-tocopherol) and manganese (III) tetrakis (1-methyl-4pyridyl) porphyrin pentachloride (MnTMPyP), a potent, membrane-permeable superoxide dismutase (SOD) mimetic. These antioxidants were selected because of their demonstrated 
effectiveness in attenuating symptoms of chronic oxidative stress in rats (Bucher and Roberts, 1982; Husain et al., 1992; Prabhakar and Kumar, 2004; Kumar et al., 2006). Whereas vitamin E primarily protects against lipid peroxidation due to its localization in hydrophobic regions of cell membranes (Wang and Quinn, 1999), MnTMPyP has a more general antioxidant function by scavenging the superoxide anion and limiting superoxide-dependent production of additional strong oxidants (Gardner et al., 1996; Christofidou-Solomidou and Muzykantov, 2006); a preliminary report on the effect of MnTMPyP on carotid body volume has been made (Bavis et al., in press). Our second approach was to determine whether $60 \% \mathrm{O}_{2}$ increased blood plasma concentrations of protein carbonyls, a widely used marker for in vivo oxidative stress (Dalle-Donne et al., 2003; Halliwell and Whiteman, 2004). If overproduction of ROS contributes to hyperoxia-induced developmental plasticity, we predicted that hyperoxic rats would exhibit increased concentrations of protein carbonyls.

\section{Methods}

Sprague-Dawley rats were used in three separate series of experiments: the effects of the antioxidants vitamin E (Series 1) and MnTMPyP (Series 2) on respiratory control development, and protein carbonyl formation during postnatal hyperoxia (Series 3). Experimental procedures were approved by the Animal Care and Use Committee at the institution where the experiments were completed, the School of Veterinary Medicine of the University of Wisconsin (Series 1) or Bates College (Series 2 and 3). All rats were maintained on a 12:12 light cycle throughout the study and provided food and water ad libitum.

\subsection{Series 1: Vitamin E supplementation}

2.1.1 Experimental animals and rearing protocols-This series of experiments consisted of four developmental treatment groups: 2 litters of rats were raised in normoxia with mothers fed a standard rodent diet (Normoxia + Control diet), 3 litters were raised in normoxia with mothers fed a diet enriched with vitamin E (1000 IU kg${ }^{-1}$; Normoxia + Vit. E), 2 litters were raised in hyperoxia with mothers fed a standard rodent diet (Hyperoxia + Control diet), and 2 litters were raised in hyperoxia with mothers fed a diet enriched with vitamin E (1000 $\mathrm{IU} \mathrm{kg}{ }^{-1}$; Hyperoxia + Vit. E).

Late gestation pregnant Sprague-Dawley rats were obtained 2-4 days before giving birth (colony 236, Harlan Sprague-Dawley, Madison, WI USA). To prepare the Hyperoxia groups, pregnant rats were placed into a large environmental chamber maintained at $60 \% \mathrm{O}_{2}$. The chamber was flushed with gases at sufficient flow rates to maintain $\mathrm{CO}_{2}$ below $0.3 \%$. The resulting litters were raised in the chamber with their mothers for the first 14 postnatal days; the chamber design enabled cages to be cleaned without opening the chamber. After the first 14 postnatal days, rats were housed in room air until studied at 3-5 months of age. Normoxia groups were housed in the same room as the Hyperoxia groups, but were born and raised in room air. Barometric pressure during developmental exposures averaged $730 \mathrm{mmHg}$.

Vitamin E ( $\alpha$-tocopherol) was supplemented in the diets of some of the Normoxia and Hyperoxia mothers. The control diet (\#8604, Harlan Teklad) contained 90 IU vitamin E $\mathrm{kg}^{-1}$. Rats receiving supplemental vitamin $\mathrm{E}$ were fed a custom diet prepared by Harlan Teklad which consisted of the normal diet formula (\#8604) enriched with an additional $1000 \mathrm{IU}$ vitamin $\mathrm{E} \mathrm{kg}^{-1}$. Control or supplemental vitamin $\mathrm{E}$ diets were provided to the pregnant mothers upon arrival and continued through postnatal day 14; all rats were fed the control diet after postnatal day 14. Although neonatal rats do not consume solid foods, vitamin $\mathrm{E}$ is transferred to pups via colostrum/milk (e.g., Pazak and Scholz, 1996).

2.1.2 Carotid sinus nerve recording-Carotid sinus nerve (CSN) recordings were made on a total of 30 male rats (5 Normoxia + Control diet, 10 Normoxia + Vit. E, 8 Hyperoxia + 
Control diet, 7 Hyperoxia + Vit. E). Methods for CSN recording have been described in detail elsewhere (Bisgard et al., 2003). Rats were initially anesthetized in a chamber containing isoflurane ( $4 \%$ in room air), followed by urethane injection $\left(0.33 \mathrm{M}, 1 \mathrm{~g} \mathrm{~kg}^{-1}\right.$, i.p.); adequacy of anesthesia was determined by absence of a withdrawal reflex and/or absence of a change in blood pressure following toe pinch; supplemental urethane was administered as needed. Femoral venous and arterial catheters were implanted for intravenous administration of drugs and periodic sampling of arterial blood gases, respectively. Rectal temperature was monitored continuously and maintained near $37^{\circ} \mathrm{C}$ with a warm circulating-water blanket. After tracheostomy, rats were artificially ventilated with continuous monitoring of end-tidal $\mathrm{CO}_{2}$. Using a ventral midline cervical incision, the CSN was dissected to its junction with the glossopharyngeal nerve and cut. The cleaned CSN was then placed on bipolar tungsten electrodes under oil for whole-nerve recording. After confirming anesthetic depth, the animal was paralyzed (pancuronium, $2.5 \mathrm{mg} \cdot \mathrm{kg}^{-1}$ i.v.). Raw nerve activity was amplified $(\times 10,000)$ and recorded on a computer (WINDAQ, Dataq, Akron, OH).

Arterial blood samples $(0.2 \mathrm{ml})$ were drawn and immediately analyzed (model ABL-500, Radiometer, Copenhagen, Denmark) at the beginning of each experiment to ensure similar $\mathrm{P}_{\mathrm{O}_{2}}, \mathrm{P}_{\mathrm{CO}_{2}}$ and $\mathrm{pH}$ among groups before recording CSN activity. For baseline conditions, blood gases were maintained near $\mathrm{P}_{\mathrm{O}_{2}}=100$ Torr, $\mathrm{P}_{\mathrm{CO}_{2}}=35-40$ Torr, and $\mathrm{pH}=7.4$ by adjusting ventilator settings and by intravenous injection of $8.4 \% \mathrm{NaHCO}_{3}$ as necessary. Actual values (mean $\pm \mathrm{SEM}$ ) for baseline arterial blood gases and $\mathrm{pH}$ were $\mathrm{P}_{\mathrm{O}_{2}}=100 \pm 2$ Torr, $\mathrm{P}_{\mathrm{CO}_{2}}=37.4$ \pm 0.5 Torr, and $\mathrm{pH}=7.40 \pm 0.01$ ( $\mathrm{n}=32$, pooled across treatment groups). The baseline CSN discharge frequency was arbitrarily set near $200 \mathrm{~Hz}$ using a window discriminator and ratemeter (models WD-1000 and RIC-1000, respectively; CWE, Ardmore, PA). Although baseline CSN activity may include chemoreceptor activity, baroreceptor activity and electrical noise, we have previously determined that setting the baseline between 200 and $300 \mathrm{~Hz}$ has minimal effect on CSN responses measured in control and hyperoxia-treated rats (Bisgard et al., 2003).

Stimuli for CSN responses were sodium cyanide ( $\mathrm{NaCN}$ ), brief asphyxia, $100 \% \mathrm{~N}_{2}$, and isocapnic hypoxia. Although each individual rat received multiple stimuli, not all rats received every stimulus (see Data Analysis, section 2.4, below); sufficient time (typically 2-5 min) was given between trials for CSN activity to return to baseline. For NaCN, 20, 40 and/or $80 \mu \mathrm{g}$ $\mathrm{kg}^{-1} \mathrm{NaCN}$ (diluted in $0.1 \mathrm{ml}$ of $0.9 \%$ sterile saline) was flushed into the intravenous catheter with $0.3 \mathrm{ml}$ of saline. The peak discharge frequency following injection was used to calculate the response to $\mathrm{NaCN}$. For asphyxia, the ventilator was turned off for $10-15 \mathrm{~s}$ and the increase in CSN discharge frequency from baseline was measured at 10s. For $100 \% \mathrm{~N}_{2}$ and isocapnic hypoxia, inspired $\mathrm{O}_{2}$ was maintained at the target level until the maximal, steady-state response was reached (1-2 $\mathrm{min})$. During hypoxia, blood gases were drawn before returning to baseline conditions. The target arterial $\mathrm{P}_{\mathrm{O}_{2}}$ during hypoxia was 45 Torr, which was usually obtained using $\mathrm{F}_{\mathrm{I}} \mathrm{O}_{2}$ of $14-16 \%$; if necessary, trials were repeated with additional $\mathrm{F}_{\mathrm{I}} \mathrm{O}_{2}$ until an arterial $\mathrm{P}_{\mathrm{O}_{2}}$ near 45 Torr was achieved. Actual measured values during the accepted trials for $\mathrm{P}_{\mathrm{O}_{2}}$ were $45 \pm 1$ Torr (mean \pm SEM; $n=14$, pooled across treatment groups).

2.1.3 Carotid body volumes-Carotid body volume was estimated for adult male rats ( $\mathrm{n}=$ 3 per treatment group). Rats were deeply anesthetized with urethane $\left(0.33 \mathrm{M}, 1 \mathrm{~g} \mathrm{~kg}^{-1}\right.$, i.p.) and transcardially perfused with saline followed by ice cold $4 \%$ paraformaldehyde in saline. The carotid bifurcation was then dissected en bloc, post-fixed in paraformaldehyde ( $24 \mathrm{~h}$ ) and cryoprotected in sucrose ( $3 \mathrm{~d}$ in $30 \%$ sucrose). Extraneous tissue was dissected away and carotid bifurcations were embedded in Tissue-Tek O.C.T. compound (Sakura Finetek, Torrance, CA USA) on dry ice and frozen sectioned $(12 \mu \mathrm{m})$ with a cryostatic microtome onto microscope slides. Slides were then processed for morphological analysis using hematoxylin staining. For those serial sections containing the carotid body, digital photoimages were 
imported into a computer using a Nikon E600 microscope and SPOT camera imaging software (Diagnostic Instruments, Sterling Heights, MI USA). The carotid body was outlined and the area calculated using Image-Pro Plus (Media Cybernetics, Silver Springs, MD USA) software; all measurements were calibrated against a micrometer. Carotid body volume was then estimated by the area of the CB on each section, section thickness, and the total number of sections containing the carotid body: $\Sigma$ [carotid body area in each section $\left(\mu \mathrm{m}^{2}\right) \times$ section thickness $(\mu \mathrm{m})]$.

\subsection{Series 2: MnTMPyP}

2.2.1 Experimental animals and rearing protocols-This series of experiments consisted of four developmental treatment groups: 6 litters of rats were raised in normoxia and injected daily with saline (Normoxia + Saline), 6 litters were raised in normoxia and injected daily with the stable SOD mimetic manganese (III) tetrakis (1-methyl-4-pyridyl) porphyrin pentachloride (5-10 mg kg-1, i.p.; Normoxia + MnTMPyP), 6 litters were raised in hyperoxia and injected daily with saline (Hyperoxia + Saline), and 6 litters were raised in hyperoxia and injected daily with MnTMPyP (5-10 $\mathrm{mg} \mathrm{kg}^{-1}$, i.p.; Hyperoxia + MnTMPyP).

Hyperoxia groups were prepared by placing timed pregnant Sprague-Dawley rats (colony 236b, Harlan Sprague-Dawley, Madison, WI USA) into environmental chambers one day before giving birth. Chambers were flushed with gases at sufficient flow rates to maintain $60 \%$ $\mathrm{O}_{2}$ and $<0.3 \% \mathrm{CO}_{2}$. The resulting litters were raised in the chamber with their mothers for the first 14 postnatal days. Pups were removed from the chamber daily to administer drugs and clean cages ( $\sim 5$ min per litter; see below), but this brief exposure to normoxia will not prevent hyperoxia-induced developmental plasticity (Bavis et al., 2007). Normoxia groups were housed in the same room as Hyperoxia, but were born and raised in room air. Barometric pressure during developmental exposures averaged $753 \mathrm{mmHg}$. After the first 14 postnatal days, all rats were housed in room air until studied at $2-3$ months of age.

Pups in half of the Hyperoxia and Normoxia litters received daily intraperitoneal injections of MnTMPyP (5 mg ml ${ }^{-1}$ in saline; Axxora, San Diego, CA USA) for the first 14 postnatal days; pups in the remaining litters were injected with an equal volume of sterile saline (0.9\%; Phoenix, St. Joseph, MO USA). Each pup was injected with $0.01 \mathrm{ml}$ per $10 \mathrm{~g}$ body mass (i.e., $0.01 \mathrm{ml}$ for $0-10.0 \mathrm{~g}, 0.02 \mathrm{ml}$ for 10.1-20.0 g, etc.); thus, MnTMPyP pups received 5-10 mg $\mathrm{kg}^{-1}$ of the drug daily depending on their mass, equal to or exceeding the effective dosage used for rats in previous studies (e.g., Peng et al., 2003; Peng and Prabhakar, 2004; Kumar et al., 2006). Although the exact time of birth was not known for pups born overnight, all Hyperoxia pups receiving MnTMPyP were injected with their first dose of the drug within 12 hours after birth; all other groups received their first injections within 17 hours of birth, generally sooner. All injections were made with 28-gauge needles and the site of injection alternated between the left and right sides of the abdomen on subsequent days.

2.2.2 Ventilation and metabolism measurements-Ventilation and metabolism measurements were made on 16 male rats from each of the four treatment groups. At least one week prior to these measurements, temperature transponders (E-mitter PDT $4000 \mathrm{G}$ or G2; Mini-Mitter, Bend, OR USA) were surgically implanted into the abdominal cavity of all rats. Anesthesia was induced with isoflurane in a closed box and subsequently maintained via nose cone $\left(\sim 2.5 \%\right.$ isoflurane, balance $\left.\mathrm{O}_{2}\right)$; adequacy of anesthesia was assessed by lack of a withdrawal response to toe pinch. Transponders were placed into the abdominal cavity through a ventral midline incision. A single dose of carprofen $\left(5 \mathrm{mg} \mathrm{kg}^{-1}\right.$, s.c.; Rimadyl, Pfizer, New York, NY USA) was provided immediately after surgery as an analgesic (Roughan and Flecknell, 2004). 
Ventilation was measured on unrestrained rats resting in a whole-body barometric plethysmograph chamber during the light portion of the light-dark cycle. Rats were placed into a clear acrylic chamber ( $14 \mathrm{~cm}$ inner diameter, 1.71 functional volume). Air was forced through the chamber at $21 \mathrm{~min}^{-1}$ (STPD) using a gas mixing mass flow controller (MFC-4; Sable Systems, Las Vegas, NV USA) and valves (series 840; Sierra Instruments, Monterey, CA USA). To ensure that the chamber air was saturated with water vapor, air was warmed and humidified before entering the chamber and the chamber floor was covered with water beneath the rat. When sealed, respiratory-related pressure fluctuations within the chamber were measured with a differential pressure transducer (DP45; Validyne Engineering, Northridge, CA USA); the system was pre-calibrated by repeated $0.1 \mathrm{ml}$ air injections. Pressure fluctuations and chamber temperature (T-type thermocouple) were recorded to computer (PowerLab 8SP and Chart 5.2 software, ADInstruments, Colorado Springs, CO USA). Body temperature $\left(\mathrm{T}_{\mathrm{b}}\right.$ ) was continuously recorded by telemetry (VitalView 4.1, Mini-Mitter, Bend, OR USA). These measurements were used to calculate tidal volume $\left(\mathrm{V}_{\mathrm{T}}\right)$ (Drorbaugh and Fenn, 1955), respiratory frequency $\left(\mathrm{f}_{\mathrm{R}}\right)$, and minute ventilation $\left(\mathrm{V}_{\mathrm{E}}\right)$. Fractional concentrations of $\mathrm{O}_{2}$ and $\mathrm{CO}_{2}$ in air entering and exiting the plethysmograph chamber were measured (PowerLab Gas Analyzer ML206, ADInstruments, Colorado Springs, CO USA) and recorded to computer to calculate metabolic $\mathrm{O}_{2}$ consumption $\left(\dot{\mathrm{V}}_{\mathrm{O}_{2}}\right)$ and $\mathrm{CO}_{2}$ production $\left(\mathrm{V}_{\mathrm{CO}_{2}}\right)$; air was dried (Direrite, W.A. Hammond Drierite Co., Xenia, OH USA) prior to passing through the gas analyzer.

On the day of the experiment, rats were weighed and placed into the plethysmograph chamber. Rats were initially exposed to $21 \% \mathrm{O}_{2}$ (balance $\mathrm{N}_{2}$ ) for at least one hour. When rats appeared calm, $\mathrm{O}_{2}$ and $\mathrm{CO}_{2}$ exiting the plethysmograph were recorded for approximately $30 \mathrm{~s}$. The chamber was then briefly sealed ( 1 $\mathrm{min})$ to record respiratory-related pressure fluctuations. Our objective was to obtain at least $30 \mathrm{~s}$ of data free from movement artifacts and sighs, and measurements were repeated if necessary. Rats were then exposed to $12.5 \% \mathrm{O}_{2}$ (balance $\mathrm{N}_{2}$ ) for 15 minutes before repeating metabolism and ventilation measurements. Although arterial blood gases were not measured in the present study, we previously observed that Hyperoxia and Normoxia rats experience equivalent degrees of arterial hypoxemia at similar inspired $\mathrm{O}_{2}$ levels (Bavis et al., 2007). Barometric pressure was recorded during each ventilation measurement and averaged $754 \mathrm{mmHg}$ during this part of the study.

2.2.3 Carotid body volumes-Carotid body volume was estimated for adult male rats ( $\mathrm{n}=$ 7 per treatment group) at least one week after the ventilation measurements were completed. Rats were deeply anesthetized by $100 \% \mathrm{CO}_{2}$ and transcardially perfused with ice cold $4 \%$ paraformaldehyde in $0.1 \mathrm{M}$ PBS ( $\mathrm{pH}=7.4)$. The carotid bifurcation was then dissected out en bloc, post-fixed in paraformaldehyde ( $1 \mathrm{~h}$ ) and cryoprotected in sucrose ( $1 \mathrm{~d}$ in $20 \%$ sucrose). Extraneous tissue was dissected away and carotid bifurcations were embedded in Tissue-Tek O.C.T. compound (Sakura Finetek, Torrance, CA USA) on dry ice and frozen sectioned (12 $\mu \mathrm{m})$ with a cryostatic microtome onto microscope slides. Slides were then processed for morphological analysis using hematoxylin staining. For those serial sections containing the carotid body, digital photoimages were imported into a computer using a Nikon TE-2000U microscope and SPOT camera imaging software (Universal Imaging Corporation, Buckinghamshire, UK). The carotid body was outlined and the area calculated using Image $\mathbf{J}$ (National Institutes of Health, Bethesda, MD USA) software; all measurements were calibrated against a micrometer. Carotid body volume was then estimated as described above (see Section 2.2.3, above).

\subsection{Series 3: Protein carbonyl concentration after perinatal hyperoxia}

2.3.1 Experimental animals and rearing protocol-This experiment consisted of two developmental treatment groups, Hyperoxia (4 litters) and Normoxia (4 litters). Hyperoxia and Normoxia groups were prepared by placing newborn Sprague-Dawley rats (Charles River 
Laboratories, Wilmington, MA) into environmental chambers immediately after birth. Chambers were flushed with gases at sufficient flow rates to maintain $60 \% \mathrm{O}_{2}$ or $21 \% \mathrm{O}_{2}$ and $<0.3 \% \mathrm{CO}_{2}$. Pups were raised in the chambers with their mothers until studied at 48 hours after birth (P2) or 8 days after birth (P8); the birth of each litter was timed so that P2 and P8 exposures were complete on the same day to facilitate tissue collection (see below). Barometric pressure during developmental exposures averaged $753 \mathrm{mmHg}$.

Although rats in this experiment were obtained from a different vendor than those used in the vitamin E and MnTMPyP experiments, we have found no qualitative differences for the effects of perinatal hyperoxia on the HVR or carotid body volume between these substrains (S.E. Piro, E.F. Dmitrieff, and R.W. Bavis, unpublished observations).

2.3.2 Protein carbonyl determination-Protein carbonyl concentrations in blood plasma were determined for neonates at P2 ( $n=7$ Hyperoxia and 6 Normoxia) and P8 ( $n=7$ pups per group); each group consisted of 3-4 males and 3-4 females. Blood samples were collected by deeply anesthetizing rat pups with isoflurane in a closed container followed by rapid decapitation. Approximately $0.5 \mathrm{ml}$ whole blood was collected, mixed with $0.1 \mathrm{ml}$ heparin (1000 units $\mathrm{ml}^{-1}$ ) and briefly stored on ice ( $\left.<15 \mathrm{~min}\right)$. Blood samples were then centrifuged for $10 \mathrm{~min}(2,000 \times \mathrm{g})$ and the plasma was transferred to a new microcentrifuge tube and stored on ice until studied $(<2 \mathrm{~h})$. All treatment groups were run on the same 96-well plate using fresh plasma samples; preliminary experiments suggested that freezing samples $\left(-70^{\circ} \mathrm{C}\right)$ for later analysis increased protein carbonyl concentrations (data not shown). Protein carbonyl concentrations were measured using a commercially available ELISA assay (ZENTECH PC Test Kit, Zenith Technology Corp., Dunedin, New Zealand). In this assay, protein carbonyls are reacted with dinitrophenylhydrazine and quantified colorimetrically against standards provided by the manufacturer; standard curves were run in duplicate during each assay. All assays were run using the Standard Procedure outlined in the kit's instructions; preliminary analysis confirmed that protein concentrations in plasma samples were within the recommended range for this procedure (Micro BCA Protein Assay Reagent Kit, Pierce Biotechnology, Rockford, IL USA). Absorbances were read at $450 \mathrm{~nm}$, corrected against reagent blanks, and used to calculate protein carbonyl concentrations (nmol protein carbonyls $(\mathrm{mg} \text { total protein) })^{-1}$ ) in the samples (Synergy HT microplate reader and KC4 v. 3.03 software, BioTek Instruments, Winooski, VT USA).

\subsection{Data analysis}

For the vitamin E experiments, CSN responses were measured as the change in discharge rate from baseline $\left(\triangle \mathrm{CSN}\right.$ activity $=$ discharge $_{\text {stimulus }}-$ discharge $\left._{\text {baseline }}\right)$. Comparisons among groups for $\mathrm{NaCN}$ and asphyxia responses were made by two-way ANOVA (developmental $\mathrm{F}_{\mathrm{I}} \mathrm{O}_{2}$ and diet) followed by Student-Newman-Keuls post hoc tests. It was not possible to run two-way ANOVA for the responses to $100 \% \mathrm{~N}_{2}$ and hypoxia due to insufficient sample sizes ( $n=1-2$ for one or more groups). Thus, these comparisons were made by collapsing treatment groups and comparing the effects of perinatal hyperoxia and/or vitamin E supplementation by independent samples t-tests, as indicated in the text.

For the MnTMPyP experiments, ventilatory variables $\left(\mathrm{V}_{\mathrm{T}}, \mathrm{f}_{\mathrm{R}}\right.$ and $\left.\mathrm{V}_{\mathrm{E}}\right)$ were calculated by breath-by-breath analysis of 30-45 s of quiet breathing. Metabolic variables $\left(\mathrm{V}_{\mathrm{O}_{2}}\right.$ and $\left.\mathrm{V}_{\mathrm{CO}_{2}}\right)$ were calculated from 30-45 s recordings of $\mathrm{O}_{2}$ and $\mathrm{CO}_{2}$ concentrations of air entering and exiting the plethysmograph chamber. These values were used to derive the ventilation-tometabolism ratio, $\mathrm{V}_{\mathrm{E}} / \mathrm{V}_{\mathrm{O}_{2}}$ or $\mathrm{V}_{\mathrm{E}} / \mathrm{V}_{\mathrm{CO}_{2}}$; preliminary analysis revealed qualitatively similar results for $\dot{\mathrm{V}}_{\mathrm{E}} / \mathrm{V}_{\mathrm{O} 2}$ or $\hat{\mathrm{V}}_{\mathrm{E}} / \hat{\mathrm{V}}_{\mathrm{CO}_{2}}$, so we have only discussed $\mathrm{V}_{\mathrm{E}} / \mathrm{V}_{\mathrm{CO}_{2}}$ below. Statistical comparisons were made among groups by two-way ANOVA (developmental $\mathrm{F}_{\mathrm{I}} \mathrm{O}_{2}$ and drug) followed by Student-Newman-Keuls post hoc tests. HVR was evaluated using both the 
percentage increase from baseline and the actual ventilatory measurements during hypoxia. Similar results were obtained when HVR was calculated as the change from baseline without normalization to baseline (data not shown).

Carotid body volumes were compared among groups by two-way ANOVA (developmental $\mathrm{F}_{\mathrm{I}} \mathrm{O}_{2}$ and either diet or drug, as appropriate) followed by Student-Newman-Keuls post hoc tests. To meet the assumptions of parametric tests, it was necessary to apply a logarithmic transformation to the carotid body volumes in the MnTMPyP experiments before running the ANOVA; for clarity, non-tranformed data are presented in Figure 4. Protein carbonyl concentrations were compared between treatment groups at each age by independent samples t-tests.

Statistical tests were run using SigmaStat v. 3.0 (Systat Software, Inc., Point Richmond, CA USA) or Prism v. 4.03 (GraphPad Software, San Diego, CA USA). Differences were considered significant at $P \leq 0.05$. Values in the text are means \pm SEM unless stated otherwise.

\section{Results}

\subsection{CSN responses after perinatal hyperoxia and vitamin $E$}

Effects of supplemental vitamin $E$ on carotid body chemoreceptor function were assessed using brief challenges with $\mathrm{NaCN}$, asphyxia, $100 \% \mathrm{~N}_{2}$, and isocapnic hypoxia.

CSN responses to intravenous injections of 80,40 and $20 \mu \mathrm{g} \mathrm{kg}^{-1} \mathrm{NaCN}$ were reduced an average of 71-77\% by developmental hyperoxia (main effect for developmental $\mathrm{F}_{\mathrm{I}} \mathrm{O}_{2}, P<0.001$ for 80 and $40 \mu \mathrm{g} \mathrm{kg}^{-1}$, and $P<0.01$ for $20 \mu \mathrm{g} \mathrm{kg}^{-1}$ ) (Fig. 1). There was no effect of vitamin E supplementation on CSN responses at any dose of $\mathrm{NaCN}$ (diet and diet $\times$ developmental $\mathrm{F}_{\mathrm{I}} \mathrm{O}_{2}$, all $P \geq 0.68$ ). As with $\mathrm{NaCN}, \mathrm{CSN}$ responses to brief asphyxia were substantially reduced in Hyperoxia rats (main effect for developmental $\mathrm{F}_{\mathrm{I}} \mathrm{O}_{2}, P<0.001$ ) (Fig. 2a), with whole-nerve activity increasing $87 \%$ less than in Normoxia rats. Vitamin E supplementation had no detectable effect on CSN responses to asphyxia (diet and diet $\times$ developmental $\mathrm{F}_{\mathrm{I}} \mathrm{O}_{2}, P=0.55$ and 0.35 , respectively).

CSN responses to $100 \% \mathrm{~N}_{2}$ (anoxia) and acute hypoxia are also shown in Figure 2 (panels B and $\mathrm{C}$, respectively). The general trends are qualitatively similar to those observed for $\mathrm{NaCN}$ and asphyxia, although sample sizes were too small to test the effects of both developmental hyperoxia and supplemental vitamin E with two-way ANOVA (i.e., one or more groups had $\mathrm{n}=2$ ). Pooling across diets, maximal CSN responses to both $100 \% \mathrm{~N}_{2}$ and isocapnic hypoxia were smaller in Hyperoxia versus Normoxia rats (independent samples t-test, both $P<0.001$ ). Indeed, the normal increase in whole-nerve activity during acute hypoxia was completely abolished in Hyperoxia rats (Fig. 2C), with five of the seven individuals exhibiting a decrease in activity during hypoxia relative to baseline; CSN activity below baseline likely reflects reduced activity of baroreceptors since blood pressure decreased during hypoxia ( $\Delta$ mean arterial blood pressure $=-46 \pm 4$ and $-46 \pm 7 \mathrm{mmHg}$ in Normoxia and Hyperoxia rats, respectively). Within the Hyperoxia rats, there was no significant effect of vitamin $\mathrm{E}$ supplementation on CSN responses to $100 \% \mathrm{~N}_{2}$ (independent samples t-test, $P=0.69$ ) (Fig. 2B). Similarly, vitamin E supplementation did not appear to improve CSN responses to acute hypoxia in Hyperoxia rats (Fig. 2C), although we could not test this observation statistically due to limited sample size.

\subsection{HVR after perinatal hyperoxia and MnTMPyP}

Baseline $\left(21 \% \mathrm{O}_{2}\right)$ ventilation and metabolism measurements for Normoxia and Hyperoxia rats treated with saline or MnTMPyP are summarized in Table 1 . $\mathrm{V}_{\mathrm{E}}$ was not significantly different between Normoxia and Hyperoxia rats (main effect for developmental $\mathrm{F}_{\mathrm{I}} \mathrm{O}_{2}, P=0.34$ ), 
although $\dot{\mathrm{V}}_{\mathrm{E}} / \dot{\mathrm{V}}_{\mathrm{CO}_{2}}$ was slightly $(9 \%)$ greater in Hyperoxia rats $(P=0.05)$. The greater $\dot{\mathrm{V}}_{\mathrm{E}} /$ $\dot{V}_{\mathrm{CO}_{2}}$ reflects an increased $\mathrm{V}_{\mathrm{T}}$ in Hyperoxia rats $(P=0.05)$; perinatal hyperoxia had no effect on baseline $f_{\mathrm{R}}(P=0.72)$ or $\dot{\mathrm{V}}_{\mathrm{CO}_{2}}(P=0.22)$. Daily injection with MnTMPyP had no effect on any of the baseline ventilatory or metabolic variables measured (drug and drug $\times$ developmental $\mathrm{F}_{\mathrm{I}} \mathrm{O}_{2}$, all $\left.P>0.05\right)$.

Ventilatory responses to $12.5 \% \mathrm{O}_{2}$ are shown in Figure 3 as both the actual values during hypoxia (panels A-D) and as the percentage change from baseline (panels E-F). Using either method to express the HVR, the $\mathrm{V}_{\mathrm{E}}$ and $\mathrm{V}_{\mathrm{E}} / \mathrm{V}_{\mathrm{CO}_{2}}$ responses were reduced by perinatal hyperoxia (main effect for developmental $\mathrm{F}_{\mathrm{I}} \mathrm{O}_{2}$, all $P<0.001$ ) (Fig 3C-F); the reduced HVR primarily reflects a lower hypoxic $f_{\mathrm{R}}$ in Hyperoxia rats $(P<0.001)$ (Fig. 3A). In contrast, there was no effect of MnTMPyP on the HVR. Actual values of $\mathrm{V}_{\mathrm{E}}$ and $\mathrm{V}_{\mathrm{E}} / \mathrm{V}_{\mathrm{CO}_{2}}$ were nearly identical in rats receiving saline or the MnTMPyP while breathing $12.5 \% \mathrm{O}_{2}$ (drug and drug $\times$ developmental $\mathrm{F}_{\mathrm{I}} \mathrm{O}_{2}$, all $P \geq 0.68$ ) (Fig. 3C-D). Likewise, there were no differences in the HVR between rats receiving saline or MnTMPyP when expressed as percentage change from baseline (Fig. 3E-F). Although there was some tendency for MnTMPyP rats to increase $\mathrm{V}_{\mathrm{E}}$ more than saline controls (Fig. 3E), this trend was not statistically significant (main effect for drug, $P=0.09$ ) and was not specific to Hyperoxia rats (drug $\times$ developmental $\mathrm{F}_{\mathrm{I}} \mathrm{O}_{2}, P=0.66$ ). Further, this trend was no longer apparent when $\mathrm{V}_{\mathrm{E}}$ was normalized to metabolic rate (i.e., $\mathrm{V}_{\mathrm{E}} / \mathrm{V}_{\mathrm{CO}_{2}}$; drug and drug $\times$ developmental $\mathrm{F}_{\mathrm{I}} \mathrm{O}_{2}, P=0.19$ and 0.78 , respectively) (Fig. $3 \mathrm{~F}$ ).

\subsection{Carotid body volumes after perinatal hyperoxia and vitamin E or MnTMPyP}

Carotid body volumes were reduced in Hyperoxia rats in both the vitamin E and MnTMPyP experiments (Fig. 4), with the average volume being only one-third that of age-matched Normoxia rats regardless of antioxidant treatment (main effect for developmental $\mathrm{F}_{\mathrm{I}} \mathrm{O}_{2}$, $P \leq 0.001$ in both experiments). There was no effect of vitamin E supplementation (diet and diet $\times$ developmental $\mathrm{F}_{\mathrm{I}} \mathrm{O}_{2}, P=0.16$ and 0.50 , respectively) or MnTMPyP (drug and drug $\times$ developmental $\mathrm{F}_{\mathrm{I}} \mathrm{O}_{2}, P=0.90$ and 0.34 , respectively) on carotid body volume. It should be noted that the trend toward increased carotid body volume in Hyperoxia rats given supplementary vitamin $E$ is due to one rat in the Hyperoxia + Control diet group having a carotid body volume only half the size observed in the other Hyperoxia rats rather than comparatively larger volumes in the vitamin E group.

\subsection{Protein carbonyls after perinatal hyperoxia}

Plasma protein carbonyl concentrations for Normoxia and Hyperoxia pups are shown in Figure 5. No differences were detected between Normoxia and Hyperoxia pups at $\mathrm{P} 2$ or at $\mathrm{P} 8$ ( $P=0.91$ and 0.09 , respectively).

\section{Discussion}

The primary finding of this study is that antioxidant supplementation had no detectable effect on hyperoxia-induced developmental plasticity of the hypoxic chemoreflex or carotid body size. Consistent with earlier reports (reviewed in Bavis, 2005), perinatal hyperoxia greatly reduced CSN and ventilatory responses to acute hypoxic stimuli in adult rats and decreased the volume of their carotid bodies. Neither supplementing dietary vitamin E nor daily injections of a SOD mimetic ameliorated these effects of chronic $60 \% \mathrm{O}_{2}$. Moreover, $60 \% \mathrm{O}_{2}$ did not increase protein carbonyl concentrations in the blood plasma of neonatal rats, suggesting that this hyperoxic exposure causes little oxidative injury systemically. Taken together, these data do not support the hypothesis that the persistent effects of perinatal hyperoxia on respiratory control are initiated through ROS-mediated $\mathrm{O}_{2}$ toxicity. 
Although the present study is the first to directly test the role of ROS in this model of developmental plasticity, its results are consistent with indirect evidence from previous studies that also cast doubt on the $\mathrm{O}_{2}$ toxicity hypothesis. First, the effects of perinatal hyperoxia are limited to a specific developmental period; exposure to 1-4 weeks of $60 \% \mathrm{O}_{2}$ has no durable effect on carotid body morphology (Erickson et al., 1998) or respiratory control (Ling et al., 1996, 1997; Bavis et al., 2002) after the second postnatal week. In contrast, animals of all ages are susceptible to $\mathrm{O}_{2}$ toxicity while breathing hyperoxic gas mixtures $>95 \% \mathrm{O}_{2}$, with young animals (born at normal postconceptual age) generally being more tolerant to hyperoxia than adults (Frank, 1991). Second, the effects of perinatal hyperoxia appear confined to the carotid body and its afferent neurons with no evidence of functional or morphological effects in other neural pathways (Ling et al., 1997; Erickson et al., 1998; Prieto-Lloret et al., 2004). There is also no evidence of impaired gas exchange after one or two weeks of $60 \% \mathrm{O}_{2}$ (Bavis et al., 2003; Bavis et al., 2007), suggesting little lung pathology following these exposures. Third, exposure to only $30 \% \mathrm{O}_{2}$ for the first $1-3$ weeks after birth decreases carotid body size and the CSN and phrenic nerve responses to acute hypoxic stimuli in rats (Eden and Hanson, 1986; Erickson et al., 1998; Bavis et al., 2003) and reduces the CSN and ventilatory responses to hypoxia in kittens (Hanson et al., 1989); this mild level of hyperoxia is widely considered safe in adults and full-term neonates (Lumb, 2005; Tin and Gupta, 2007), with low risk of $\mathrm{O}_{2}$ toxicity even for airways and lungs where tissue $\mathrm{P}_{\mathrm{O}_{2}}$ is highest. Finally, preliminary histological studies of cell division (by labeling with bromodeoxyuridine, BrdU) and cell death (by TdT-mediated dUTP-X nick end labeling, TUNEL) suggest that hyperoxia reduces carotid body size by inhibiting its growth rather than killing existing cells (Wang and Bisgard, 2005). All of these observations point to a mechanism other than classical $\mathrm{O}_{2}$ toxicity for hyperoxia-induced changes in carotid body development.

\subsection{Methodological considerations}

The strength of our conclusion that ROS-mediated $\mathrm{O}_{2}$ toxicity contributes little to this model of developmental plasticity clearly depends on the effectiveness of vitamin E and MnTMPyP as antioxidants. Although the possibility that another antioxidant or combination of antioxidants would have been more effective cannot be ruled out, these antioxidants were selected specifically because they defend against critical ROS (superoxide anion) and ROSmediated damage (lipid peroxidation) produced during hyperoxic exposures (Jamieson et al., 1986).

Vitamin E, which contributes to the cellular defense against ROS by scavenging lipid peroxyl radicals, is a part of the body's natural defenses against hyperoxia-induced oxidative stress (Wang and Quinn, 1999; Lee et al., 2005). Vitamin E was supplemented through the maternal diet to facilitate continuous delivery to the neonates throughout the hyperoxic exposure via the maternal milk. Although vitamin E levels were not measured in the present study, this approach has previously been shown to increase vitamin $\mathrm{E}$ in the tissues of neonatal rats (Pazak and Scholz, 1996) and other mammals (e.g., Capper et al., 2005). Importantly, many studies support the use of dietary vitamin $\mathrm{E}$ supplementation to defend against ROS-mediated $\mathrm{O}_{2}$ toxicity in humans and various animal models (Christofidou-Solomidou and Muzykantov, 2006). In neonatal rats, for example, supplemental vitamin E prevents some, but not all, symptoms of bronchopulmonary dysplasia following six days at $>95 \% \mathrm{O}_{2}$, including protection against changes in gas exchange and lung compliance (Bucher and Roberts, 1982). Similarly, vitamin E has been shown to protect against pulmonary toxicity in weanling and adult rats (North et al., 1984; Husain et al., 1992). Finally, vitamin E blocks cellular damage and apoptosis in PC12 cells during hyperoxic exposures in vitro (Takahashi et al., 1998).

MnTMPyP is an effective scavenger for the superoxide anion (Gardner et al., 1996; Kumar et al., 2006), and there is considerable evidence that the superoxide anion forms during exposure 
to hyperoxia and is a major contributor to $\mathrm{O}_{2}$ toxicity (Jamieson et al., 1986; Fabian et al., 2004). Previous studies have shown that once-daily injections of MnTMPyP and related molecules are sufficient to prevent a range of cardiorespiratory changes during chronic oxidative stress in vivo (Lee and Park, 2004; Prabhakar and Kumar, 2004; Kumar et al., 2006; Peng et al., 2006). In particular, MnTMPyP abolishes ROS-dependent respiratory plasticity at the carotid body chemoreceptors following chronic intermittent hypoxia $(\mathrm{CIH})$, including $\mathrm{CIH}$-induced increases in $\mathrm{O}_{2}$ sensitivity of the carotid body (Peng and Prabhakar, 2004) and the induction of sensory long-term facilitation (Peng et al., 2003); MnTMPyP was effective even if injections were given for 10 days prior to, but not during, CIH exposure (Peng et al., 2003), confirming the stability of this drug. Collectively, these published studies validate the use of daily, systemic injections of MnTMPyP to scavenge carotid body ROS in the present study. Although little information is available concerning the application of MnTMPyP during hyperoxic exposures, this drug has been shown to protect fetal lung tissue explants from $\mathrm{O}_{2}$ toxicity in vitro (Wilborn et al., 1996).

Given the general effectiveness of vitamin E and MnTMPyP as antioxidants, the failure of our treatments to block the effects of perinatal hyperoxia probably does not reflect the choice of antioxidants or the method of delivery. In the MnTMPyP experiments, however, some neonates were exposed to $60 \% \mathrm{O}_{2}$ for up to 12 hours before the first dose was administered. It is unlikely that this brief, "unprotected" exposure to hyperoxia affected the outcome of the study since (1) a 24-hour exposure to $60 \% \mathrm{O}_{2}$ has no persistent effect on phrenic nerve responses to acute hypoxia (Bavis et al., 2003) and (2) recent experiments indicate that morphological changes in the carotid body are not apparent until the fourth day of exposure (S.E. Piro, E.F. Dmitrieff, and R.W. Bavis, unpublished observations).

\subsection{Alternative mechanisms of hyperoxia-induced developmental plasticity}

If ROS-mediated $\mathrm{O}_{2}$ toxicity does not explain changes in carotid body size and hypoxic chemoreflexes after perinatal hyperoxia, how does hyperoxia initiate this plasticity? It is possible that hyperoxia directly influences the expression of developmentally important genes through $\mathrm{O}_{2}$-sensitive transcription factors, although many of these transcription factors are themselves regulated by changes in ROS production and may have been blocked by the antioxidant treatments used in this study (Michiels et al., 2002). Whereas hyperoxia is typically associated with increased generation of ROS, it is also possible that hyperoxia influences cell signaling by decreasing the availability of ROS. Indeed, increased ROS production during hypoxia has been implicated in the $\mathrm{O}_{2}$ sensing mechanism of the carotid body glomus cells, although the specific role of ROS is not yet clear (Dinger et al., 2007; Gonzalez et al., 2007). Thus, hyperoxia potentially could influence carotid body development by attenuating normal, hypoxia-mediated ROS production. Contrary to this hypothesis, there was no effect of antioxidant treatment on the hypoxic responses of normoxia-reared rats in the current study (Figs. 1-3).

Hyperoxia inhibits the spontaneous activity of peripheral chemoreceptors, so an alternative hypothesis is that hyperoxia disrupts normal, activity-dependent development of the carotid body and its chemoafferent pathway. Indeed, activity is an important modulator of development in many neural systems by altering gene expression and releasing neurotrophic factors (Kandel et al., 2000; Moody and Bosma, 2005). Further, activity is known to regulate the maturation of dopaminergic carotid chemoafferent neurons (Hertzberg et al., 1995; Brosenitsch \& Katz 2002). If hyperoxia alters development of the carotid body by silencing its normal activity, it should be possible to rescue the HVR by experimentally increasing carotid body activity during developmental exposure to hyperoxia. Consistent with this hypothesis, rats exposed to intermittent hypercapnia throughout their exposure to perinatal hyperoxia exhibited greater HVR than rats exposed to hyperoxia alone (Bavis et al., 2007). In contrast, intermittent 
hypercapnia had no effect on the HVR in normoxia-reared rats, arguing against the possibility that the improved HVR reflects a nonspecific effect of intermittent hypercapnia on respiratory control (Bavis et al., 2007). Instead, hypercapnia likely increased carotid body activity and enabled normal activity-dependent development. Additional experiments are needed, however, to confirm that intermittent hypercapnia improves carotid body size and function in these rats. Further, non-activity-dependent pathways may also contribute to this plasticity since the HVR still tended to be lower than that of normoxia-reared rats (Bavis et al., 2007).

\subsection{Implications}

Studies on human infants and various animal models reveal that $\mathrm{O}_{2}$ levels during the perinatal period have profound effects on the development of the respiratory control system. Both abnormally high and abnormally low $\mathrm{O}_{2}$ levels alter peripheral chemoreceptors and impact hypoxic chemoreflexes (Bavis, 2005), and these changes may increase the risk of sudden infant death syndrome (Gauda et al., 2007). The present study demonstrates once again that perinatal hyperoxia impairs carotid body development in rats. Supplemental $\mathrm{O}_{2}$ is a common therapy for human infants born prematurely or in situations where arterial $\mathrm{P}_{\mathrm{O}_{2}}$ is below "normal", although there is much uncertainty concerning what $\mathrm{O}_{2}$ levels are safe (Tin and Gupta, 2007). Clinically, care is given to limit hyperoxic exposures to minimize the occurrence of retinopathy of prematurity and pulmonary toxicity, the latter being linked to ROS. If hyperoxia can impair ventilatory chemoreflexes independent of ROS production, as the present study indicates, some adverse effects of $\mathrm{O}_{2}$ therapy may go undetected in the absence of outward signs of ROS-mediated $\mathrm{O}_{2}$ toxicity. This possibility merits further investigation. Indeed, infants that receive $\mathrm{O}_{2}$ therapy in neonatal intensive care units have been found to exhibit attenuated hypoxic chemoreflexes (Katz-Salamon \& Lagercrantz, 1994), although a causal link between $\mathrm{O}_{2}$ therapy and impaired chemoreflexes has not been established in humans.

The present study only considered the effects of perinatal hyperoxia on rats born at normal gestational age. Premature infants are generally more susceptible to $\mathrm{O}_{2}$ toxicity since antioxidant defenses undergo considerable development late in gestation, just prior to birth (Frank, 1991). Thus, ROS could have a greater impact on neural control of breathing in premature infants given $\mathrm{O}_{2}$ therapy, particularly since even room air is hyperoxic relative to the environment in utero; to our knowledge, the effects of hyperoxia on respiratory control have not been evaluated experimentally in premature animals. Indeed, exposure to very high $\mathrm{P}_{\mathrm{O}_{2}}$ (near $100 \% \mathrm{O}_{2}$ normobaric, or hyperbaric $\mathrm{O}_{2}$ ) alters the function of the carotid body (Lahiri et al., 1987; Mokashi and Lahiri, 1991; Mokashi et al., 1994; Di Giulio et al., 1998) and other respiratory neurons (Dean et al., 2004), and some of these effects are likely caused by overproduction of ROS. The present study shows, however, that overproduction of ROS may not be required for moderate hyperoxia to impair respiratory control development.

\section{Acknowledgements}

The authors thank Kyle Dunmire for technical assistance. This work was supported by National Institutes of Health grants P20 RR-016463 from the INBRE Program of the National Center for Research Resources and HL-68255 from the National Heart, Lung and Blood Institute.

\section{References}

Bavis RW. Developmental plasticity of the hypoxic ventilatory response after perinatal hyperoxia and hypoxia. Respir Physiol Neurobiol 2005;149:287-299. [PubMed: 16203217]

Bavis RW, Olson EB Jr, Mitchell GS. Critical developmental period for hyperoxia-induced blunting of hypoxic phrenic responses in rats. J Appl Physiol 2002;92:1013-1018. [PubMed: 11842034]

Bavis RW, Olson EB Jr, Vidruk EH, Bisgard GE, Mitchell GS. Level and duration of developmental hyperoxia influence impairment of hypoxic phrenic responses in rats. J Appl Physiol 2003;95:15501559. [PubMed: 12819216] 
Bavis RW, Russell KER, Simons JC, Otis JP. Hypoxic ventilatory responses in rats after hypercapnic hyperoxia and intermittent hyperoxia. Respir Physiol Neurobiol 2007;155:193-202. [PubMed: 16880011]

Bavis RW, Powell FL, Bradford A, Hsia CCW, Peltonen JE, Soliz J, Zeis B, Fergusson EK, Fu Z, Gassmann M, Kim CB, Maurer J, McGuire M, Miller BM, O'Halloran KD, Paul RJ, Reid SG, Rusko HK, Tikkanen HO, Wilkinson KA. Respiratory plasticity in response to changes in oxygen supply and demand. Integr Comp Biol. In press

Bisgard GE, Olson EB Jr, Wang ZY, Bavis RW, Fuller DD, Mitchell GS. Adult carotid chemoafferent responses to hypoxia after 1, 2, and 4 wk of postnatal hyperoxia. J Appl Physiol 2003;95:946-952. [PubMed: 12909596]

Brosenitsch TA, Katz DM. Expression of Phox 2 transcription factors and induction of the dopaminergic phenotype in primary sensory neurons. Mol Cell Neurosci 2002;20:447-457. [PubMed: 12139921]

Bucher JR, Roberts RJ. The development of the newborn rat lung in hyperoxia: a dose-response study of lung growth, maturation, and changes in antioxidant enzyme activities. Pediatr Res 1981;15:9991008. [PubMed: 7254958]

Bucher JR, Roberts RJ. Effects of $\alpha$-tocopherol treatment on newborn rat lung development and injury in hyperoxia. Pediatr Pharmacol 1982;2:1-9.

Capper JL, Wilkinson RG, Kasapidou E, Pattinson SE, Mackenzie AM, Sinclair LA. The effect of dietary vitamin $\mathrm{E}$ and fatty acid supplementation of pregnant and lactating ewes on placental and mammary transfer of vitamin E to the lamb. Br J Nutr 2005;93:549-557. [PubMed: 15946419]

Christofidou-Solomidou M, Muzykantov VR. Antioxidant strategies in respiratory medicine. Treat Respir Med 2006;5:47-78. [PubMed: 16409015]

Dalle-Donne I, Giustarini D, Colombo R, Rossi R, Milzani A. Protein carbonylation in human diseases. Trends Mol Med 2003;9:169-176. [PubMed: 12727143]

Dean JB, Mulkey DK, Henderson RA, Potter SJ, Putnam RW. Hyperoxia, reactive oxygen species, and hyperventilation: oxygen sensitivity of brain stem neurons. J Appl Physiol 2004;96:784-791. [PubMed: 14715688]

Di Giulio C, Di Muzio M, Sabatino G, Spoletini L, Amicarelli F, Di Ilio C, Modesti A. Effect of chronic hyperoxia on young and old rat carotid body ultrastructure. Exp Gerontol 1998;33:319-329. [PubMed: 9639168]

Dinger B, He L, Chen J, Liu X, Gonzalez C, Obeso A, Sanders K, Hoidal J, Stensaas L, Fidone S. The role of NADPH oxidase in carotid body arterial chemoreceptors. Respir Physiol Neurobiol 2007;157:45-54. [PubMed: 17223613]

Donnelly DF, Kim I, Carle C, Carroll JL. Perinatal hyperoxia for 14 days increases nerve conduction time and the acute unitary response to hypoxia of rat carotid body chemoreceptors. J Appl Physiol 2005;99:114-119. [PubMed: 15731397]

Dröge W. Free radicals in the physiological control of cell function. Physiol Rev 2002;82:47-95. [PubMed: 11773609]

Drorbaugh JE, Fenn WO. A barometric method for measuring ventilation in newborn infants. Pediatrics 1955;16:81-87. [PubMed: 14394741]

Eden GJ, Hanson MA. Effect of hyperoxia from birth on the carotid chemoreceptor and ventilatory responses of rats to acute hypoxia. J Physiol 1986;374:24P.

Erickson JT, Mayer C, Jawa A, Ling L, Olson EB Jr, Vidruk EH, Mitchell GS, Katz DM. Chemoafferent degeneration and carotid body hypoplasia following chronic hyperoxia in newborn rats. J Physiol 1998;509:519-526. [PubMed: 9575300]

Fabian RH, Perez-Polo JR, Kent TA. Extracellular superoxide concentration increases following cerebral hypoxia but does not affect cerebral blood flow. Int J Dev Neurosci 2004;22:225-230. [PubMed: 15245758]

Frank L. Developmental aspects of experimental pulmonary oxygen toxicity. Free Rad Biol Med 1991;11:463-494. [PubMed: 1769607]

Fuller DD, Bavis RW, Vidruk EH, Wang ZY, Olson EB Jr, Bisgard GE, Mitchell GS. Life-long impairment of hypoxic phrenic responses in rats following 1 month of developmental hyperoxia. $\mathrm{J}$ Physiol 2002;538:947-955. [PubMed: 11826178] 
Gardner PR, Nguyen DDH, White CW. Superoxide scavenging by Mn(II/III) tetrakis (1-methyl-4pyridyl) porphyrin in mammalian cells. Arch Biochem Biophys 1996;325:20-28. [PubMed: 8554339]

Gauda EB, Cristofalo E, Nunez J. Peripheral arterial chemoreceptors and sudden infant death syndrome. Respir Physiol Neurobiol 2007;157:162-170. [PubMed: 17446144]

Gonzalez C, Agapito MT, Rocher A, Gonzalez-Martin MC, Vega-Agapito V, Gomez-Niño A, Rigual R, Castañeda J, Obeso A. Chemoreception in the context of the general biology of ROS. Respir Physiol Neurobiol 2007;157:30-44. [PubMed: 17331812]

Halliwell B, Whiteman M. Measuring reactive oxygen species and oxidative damage in vivo and in cell culture: how should you do it and what do the results mean? Br J Pharmacol 2004;142:231-255. [PubMed: 15155533]

Hanson, MA.; Eden, GJ.; Nijhuis, JG.; Moore, PJ. Peripheral chemoreceptors and other oxygen sensors in the fetus and newborn. In: Lahiri, S.; Forster, RE.; Davies, RO.; Pack, AI., editors. Chemoreceptors and Reflexes in Breathing: Cellular and Molecular Aspects. Oxford University Press; New York: 1989. p. 113-120.

Hertzberg T, Brosenitsch T, Katz DM. Depolarizing stimuli induce high levels of dopamine synthesis in fetal rat sensory neurons. NeuroReport 1995;7:233-237. [PubMed: 8742459]

Husain K, Sugendran K, Pant SC, Sharma VP, Vijayaraghavan R. Biochemical and pathological changes in response to hyperoxia and protection by antioxidants in rats. Indian J Physiol Pharmacol 1992;36:97-100. [PubMed: 1506090]

Jamieson D, Chance B, Cadenas E, Boveris A. The relation of free radical production to hyperoxia. Ann Rev Physiol 1986;48:703-719. [PubMed: 3010832]

Kandel, ER.; Jessell, TM.; Sanes, JR. Sensory experience and the fine-tuning of synaptic connections. In: Kandel, ER.; Schwartz, JH.; Jessell, TM., editors. Principles of Neural Science. 4. McGraw-Hill; NewYork: 2000. p. 1115-1130.

Katz-Salamon M, Lagercrantz H. Hypoxic ventilatory defense in very preterm infants: attenuation after long term oxygen treatment. Arch Dis Child Fetal Neonatal Ed 1994;70:F90-F95. [PubMed: 8154920]

Kietzmann T, Görlach A. Reactive oxygen species in the control of hypoxia-inducible factor-mediated gene expression. Sem Cell Dev Biol 2005;16:474-486.

Kumar GK, Rai V, Sharma SD, Ramakrishnan DP, Peng YJ, Souvannakitti D, Prabhakar NR. Chronic intermittent hypoxia induces hypoxia-evoked catecholamine efflux in adult rat adrenal medulla via oxidative stress. J Physiol 2006;575:229-239. [PubMed: 16777938]

Kwak DJ, Kwak SD, Gauda EB. The effect of hyperoxia on reactive oxygen species (ROS) in rat petrosal ganglion neurons during development using organotypic slices. Pediatr Res 2006;60:371-376. [PubMed: 16940233]

Lahiri S, Mulligan E, Andronikou S, Shirahata M, Mokashi A. Carotid body chemosensory function in prolonged normobaric hyperoxia in the cat. J Appl Physiol 1987;62:1924-1931. [PubMed: 3110124]

Lee JH, Park JW. A manganese porphyrin complex is a novel radiation protector. Free Radic Biol Med 2004;37:272-283. [PubMed: 15203198]

Lee ES, Smith WE, Quach HT, Jones BD, Santilli SM, Vatassery GT. Moderate hyperoxia (40\%) increases antioxidant levels in mouse tissue. J Surg Res 2005;127:80-84. [PubMed: 15921701]

Ling L, Olson EB Jr, Vidruk EH, Mitchell GS. Attenuation of the hypoxic ventilatory response in adult rats following one month of perinatal hyperoxia. J Physiol 1996;495:561-571. [PubMed: 8887766]

Ling L, Olson EB Jr, Vidruk EH, Mitchell GS. Developmental plasticity of the hypoxic ventilatory response. Respir Physiol 1997;110:261-268. [PubMed: 9407619]

Lumb, AB. Nunn's Applied Respiratory Physiology. 6. Elsevier; Philadelphia: 2005.

Michiels C, Minet E, Mottet D, Raes M. Regulation of gene expression by oxygen: NF- $\mathrm{B}$ and HIF-1, two extremes. Free Rad Biol Med 2002;33:1231-1242. [PubMed: 12398931]

Mokashi A, Lahiri S. Aortic and carotid body chemoreception in prolonged hyperoxia in the cat. Respir Physiol 1991;86:233-243. [PubMed: 1780602]

Mokashi A, Di Guilio C, Morelli L, Lahiri S. Chronic hyperoxic effects on cat carotid body catecholamines and structure. Respir Physiol 1994;97:25-32. [PubMed: 8091022] 
Moody WJ, Bosma MM. Ion channel development, spontaneous activity, and activity-dependent development in nerve and muscle cells. Physiol Rev 2005;85:883-941. [PubMed: 15987798]

North LN, Mathias MM, Schatte CL. Effect of dietary vitamin E or selenium on prostaglandin dehydrogenase in hyperoxic rat lung. Aviat Space Environ Med 1984;55:617-619. [PubMed: 6087785]

O'Reilly MA. DNA damage and cell cycle checkpoints in hyperoxic lung injury: braking to facilitate repair. Am J Physiol 2001;281:L291-L305.

Pazak HE, Scholz RW. Effects of maternal vitamin E and selenium status during the perinatal period on age-related changes in tissue concentration of vitamin $\mathrm{E}$ in rat pups. Internat $\mathrm{J}$ Vit Nutr Res 1996;66:126-133.

Peng YJ, Prabhakar NR. Effect of two paradigms of chronic intermittent hypoxia on carotid body sensory activity. J Appl Physiol 2004;96:1236-1242. [PubMed: 14660510]

Peng YJ, Overholt JL, Kline D, Kumar GK, Prabhakar NR. Induction of sensory long-term facilitation in the carotid body by intermittent hypoxia: implications for recurrent apneas. Proc Natl Acad Sci USA 2003;100:10073-10078. [PubMed: 12907705]

Peng YJ, Yuan G, Ramakrishnan D, Sharma SD, Bosch-Marce M, Kumar GK, Semenza GL, Prabhakar NR. Heterozygous HIF-1a deficiency impairs carotid body-mediated systemic responses and reactive oxygen species generation in mice exposed to intermittent hypoxia. J Physiol 2006;577:705-716. [PubMed: 16973705]

Prabhakar NR, Kumar GK. Oxidative stress in the systemic and cellular responses to intermittent hypoxia. Biol Chem 2004;385:217-221. [PubMed: 15134334]

Prieto-Lloret J, Caceres AI, Obeso A, Rocher A, Rigual R, Agapito MT, Bustamante R, Castañeda J, Perez-Garcia MT, López-López JR, González C. Ventilatory responses and carotid body function in adult rats perinatally exposed to hyperoxia. J Physiol 2004;554:126-144. [PubMed: 14678497]

Roughan JV, Flecknell PA. Behaviour-based assessment of the duration of laparotomy-induced abdominal pain and the analgesic effects of carprofen and buprenorphine in rats. Behav Pharmacol 2004;15:461-472. [PubMed: 15472568]

Takahashi H, Kosaka N, Nakagawa S. $\alpha$-Tocopherol protects PC12 cells from hyperoxia-induced apoptosis. J Neurosci Res 52:184-191. [PubMed: 9579408]

Tin W, Gupta S. Optimum oxygen therapy in preterm babies. Arch Dis Child fetal Neonatal Ed 2007;92:F143-147. [PubMed: 17337663]

Wang X, Quinn PJ. Vitamin E and its function in membranes. Prog Lipid Res 1999;38:309-336. [PubMed: 10793887]

Wang ZY, Bisgard GE. Postnatal growth of the carotid body. Respir Physiol Neurobiol 2005;149:181190. [PubMed: 15914098]

Wilborn AM, Evers LB, Canada AT. Oxygen toxicity to the developing lung of the mouse: role of reactive oxygen species. Pediatr Res 1996;40:225-232. [PubMed: 8827770] 


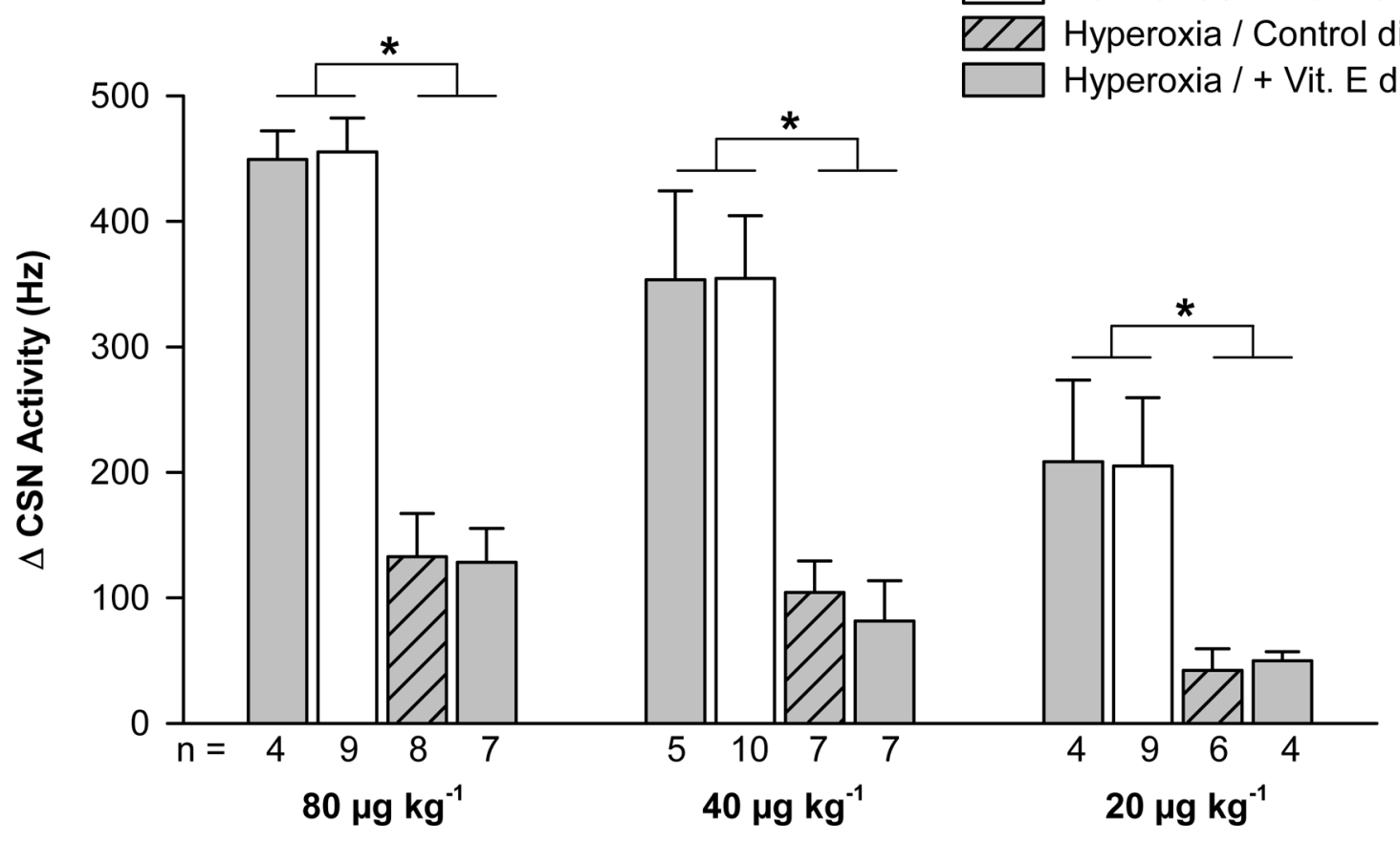

Fig. 1.

Carotid sinus nerve (CSN) responses to $\mathrm{NaCN}\left(80,40\right.$, and $\left.20 \mu \mathrm{g} \mathrm{kg}^{-1}\right)$ for adult, normoxiareared (Normoxia) and hyperoxia-reared (Hyperoxia) rats. Rats were raised with mothers fed a standard laboratory diet (Control diet) or a diet enriched with vitamin E (+ Vit. E diet) through postnatal week 2 . Changes in CSN activity are reported as means \pm S.E.M.; sample sizes (n) are given beneath each bar. Statistical analyses were run separately at each concentration of NaCN. $* P \leq 0.05$ for Normoxia versus Hyperoxia groups (i.e., main effect for developmental $\mathrm{F}_{\mathrm{I}} \mathrm{O}_{2}$ ). No differences were detected between Control and Vitamin E diets (two-way ANOVA; diet and diet $\times$ developmental $\mathrm{F}_{\mathrm{I}} \mathrm{O}_{2}$, all $P>0.05$ ). 
A
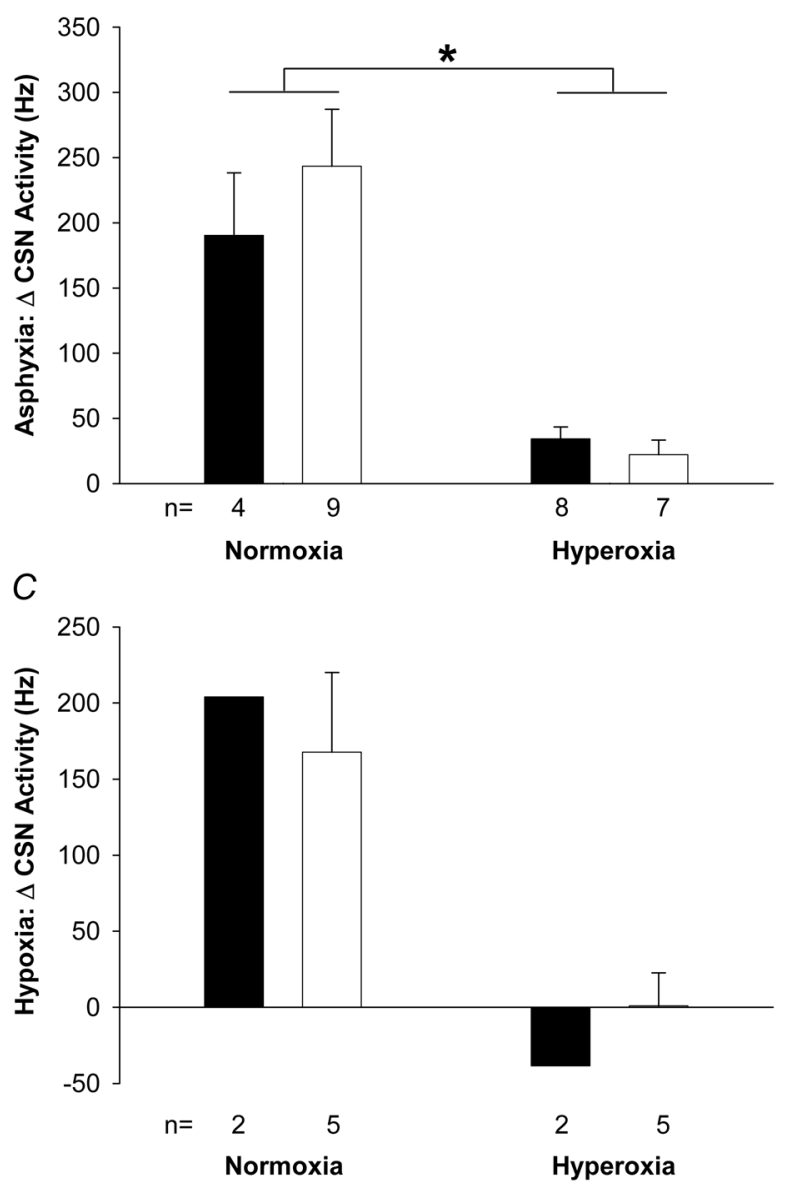

$B$

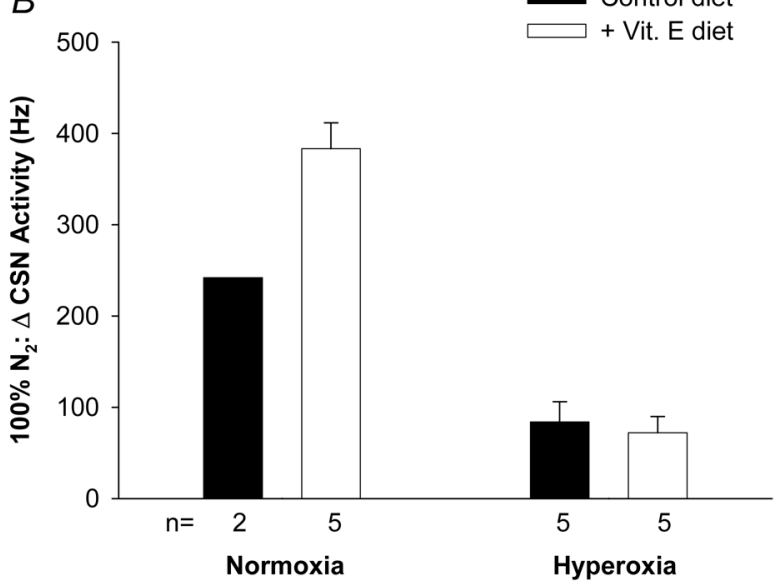

Fig. 2.

Carotid sinus nerve (CSN) responses to (A) asphyxia, (B) $100 \% \mathrm{~N}_{2}$, and (C) isocapnic hypoxia for adult, normoxia-reared (Normoxia) and hyperoxia-reared (Hyperoxia) rats. Rats were raised with mothers fed a standard laboratory diet (Control diet) or a diet enriched with vitamin E (+ Vit. E diet) through postnatal week 2 . Changes in CSN activity are reported as means \pm S.E.M.; sample sizes (n) are given beneath each bar. For asphyxia, $* P \leq 0.05$ for Normoxia versus Hyperoxia groups (i.e., main effect for developmental $\mathrm{F}_{\mathrm{I}} \mathrm{O}_{2}$ ); no differences were detected between Control and Vitamin E diets (two-way ANOVA; diet and diet $\times$ developmental $\mathrm{F}_{\mathrm{I}} \mathrm{O}_{2}$, both $P>0.05$ ). For $100 \% \mathrm{~N}_{2}$ and isocapnic hypoxia, CSN responses were not compared by two-way ANOVA due to insufficient sample sizes; see text for details. 
A

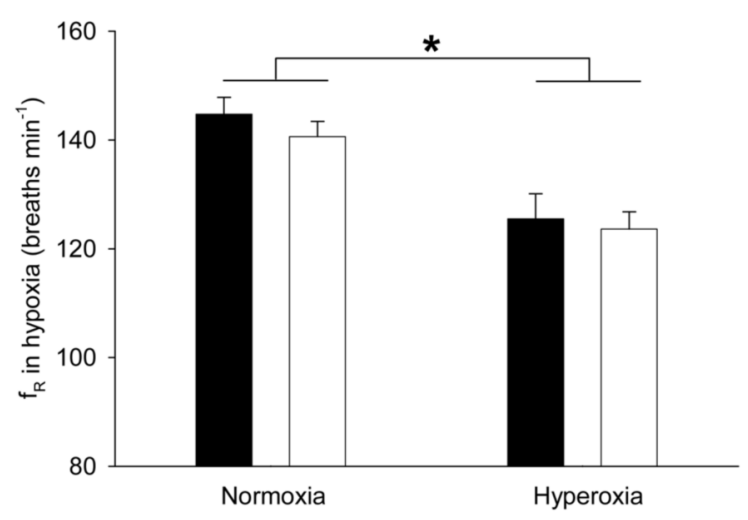

C

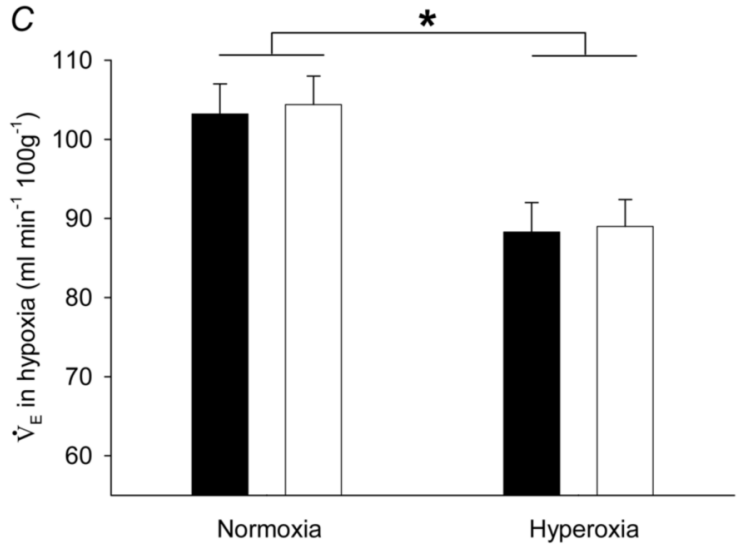

E

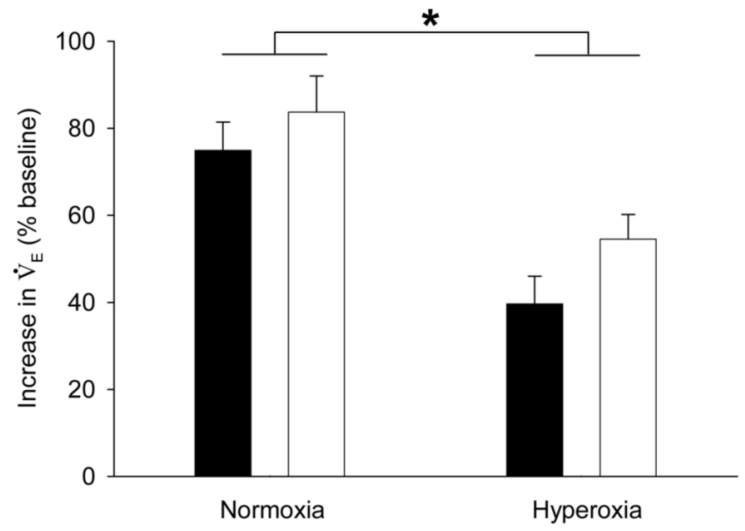

$B$
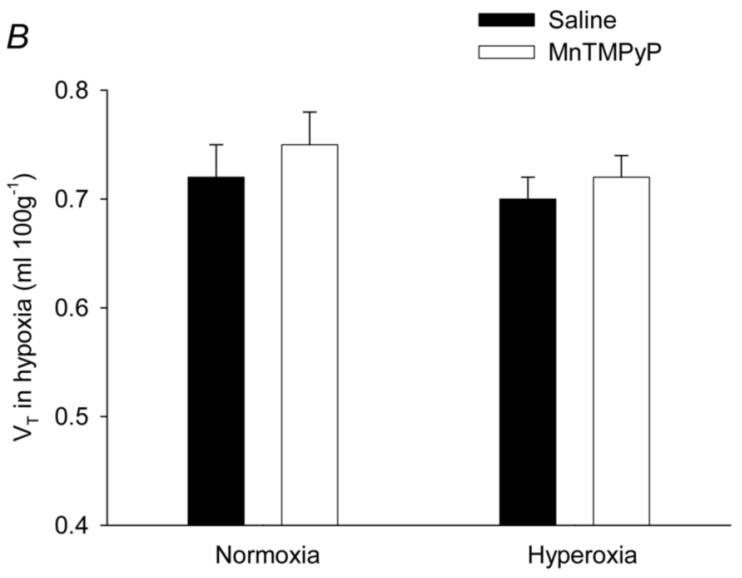

$D$

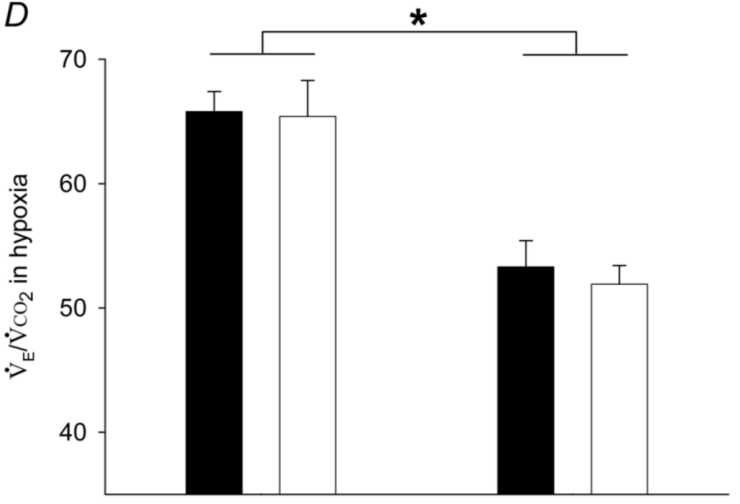

Normoxia

Hyperoxia

$F$

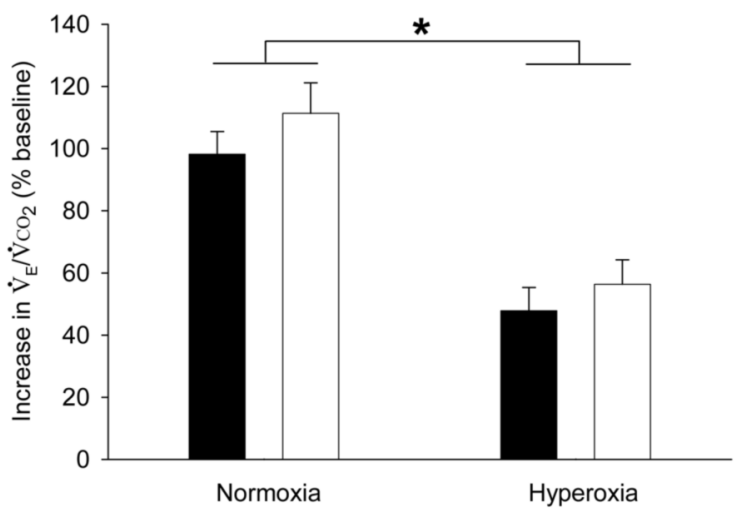

Fig. 3.

Ventilatory response to hypoxia $\left(12.5 \% \mathrm{O}_{2}\right)$ for adult, normoxia-reared (Normoxia) and hyperoxia-reared (Hyperoxia) rats treated with saline or MnTMPyP through postnatal week 2. Panels A-D present respiratory frequency $\left(\mathrm{f}_{\mathrm{R}}\right)$, tidal volume $\left(\mathrm{V}_{\mathrm{T}}\right)$, minute ventilation $\left(\mathrm{V}_{\mathrm{E}}\right)$ and ventilation-to-metabolism ratio $\left(\mathrm{V}_{\mathrm{E}} / \mathrm{V}_{\mathrm{O}_{2}}\right)$ for rats breathing hypoxic gas mixtures. In panels $\mathrm{E}$ and $\mathrm{F}, \mathrm{V}_{\mathrm{E}}$ and $\mathrm{V}_{\mathrm{E}} / \mathrm{V}_{\mathrm{O}_{2}}$ responses are presented as the percentage increase from baseline. Values are means \pm S.E.M.; $\mathrm{n}=16$ per group. $* P \leq 0.05$ for Normoxia versus Hyperoxia groups (i.e., main effect for developmental $\mathrm{F}_{\mathrm{I}} \mathrm{O}_{2}$ ). No differences were detected between saline-treated and MnTMPyP-treated groups (two-way ANOVA; drug and treatment $\mathrm{x}$ drug, all $P>0.05$ ). 

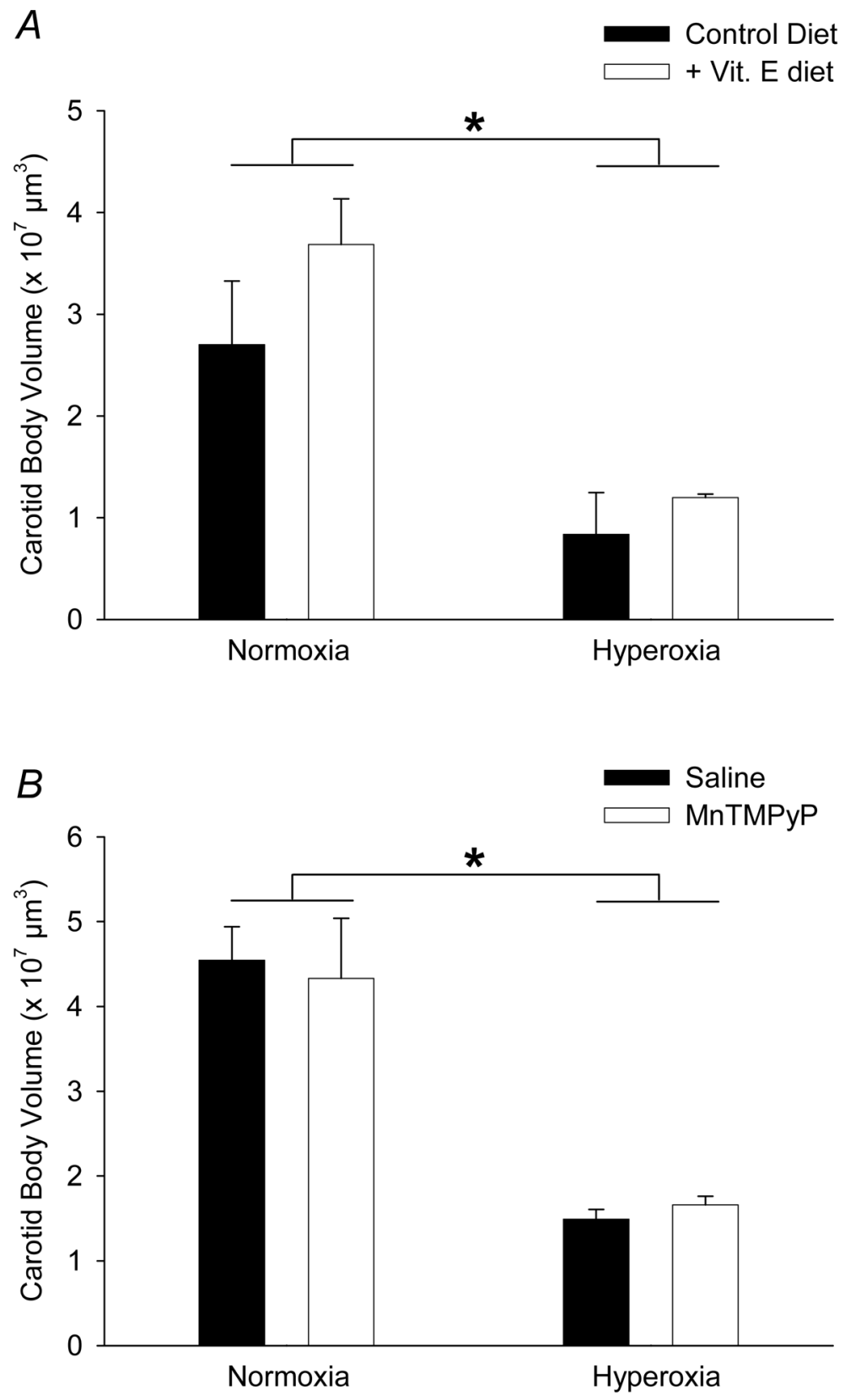

Fig. 4.

Carotid body volumes for adult, normoxia-reared (Normoxia) and hyperoxia-reared (Hyperoxia) rats. In panel A, rats were raised with mothers fed a standard laboratory diet (Control diet) or a diet enriched with vitamin E (+ Vit. E diet) through postnatal week 2. In panel B, rats were treated with saline or MnTMPyP through postnatal week 2. Values are means \pm S.E.M.; $\mathrm{n}=3$ per group in panel $\mathrm{A}$ and $\mathrm{n}=7$ per group in panel $\mathrm{B}$. ${ }^{*} P \leq 0.05$ for Normoxia versus Hyperoxia groups (i.e., main effect for developmental $\mathrm{F}_{\mathrm{I}} \mathrm{O}_{2}$ ). No effects of antioxidant treatments were detected (two-way ANOVA; main effects and interactions, all $P>0.05$ ). 


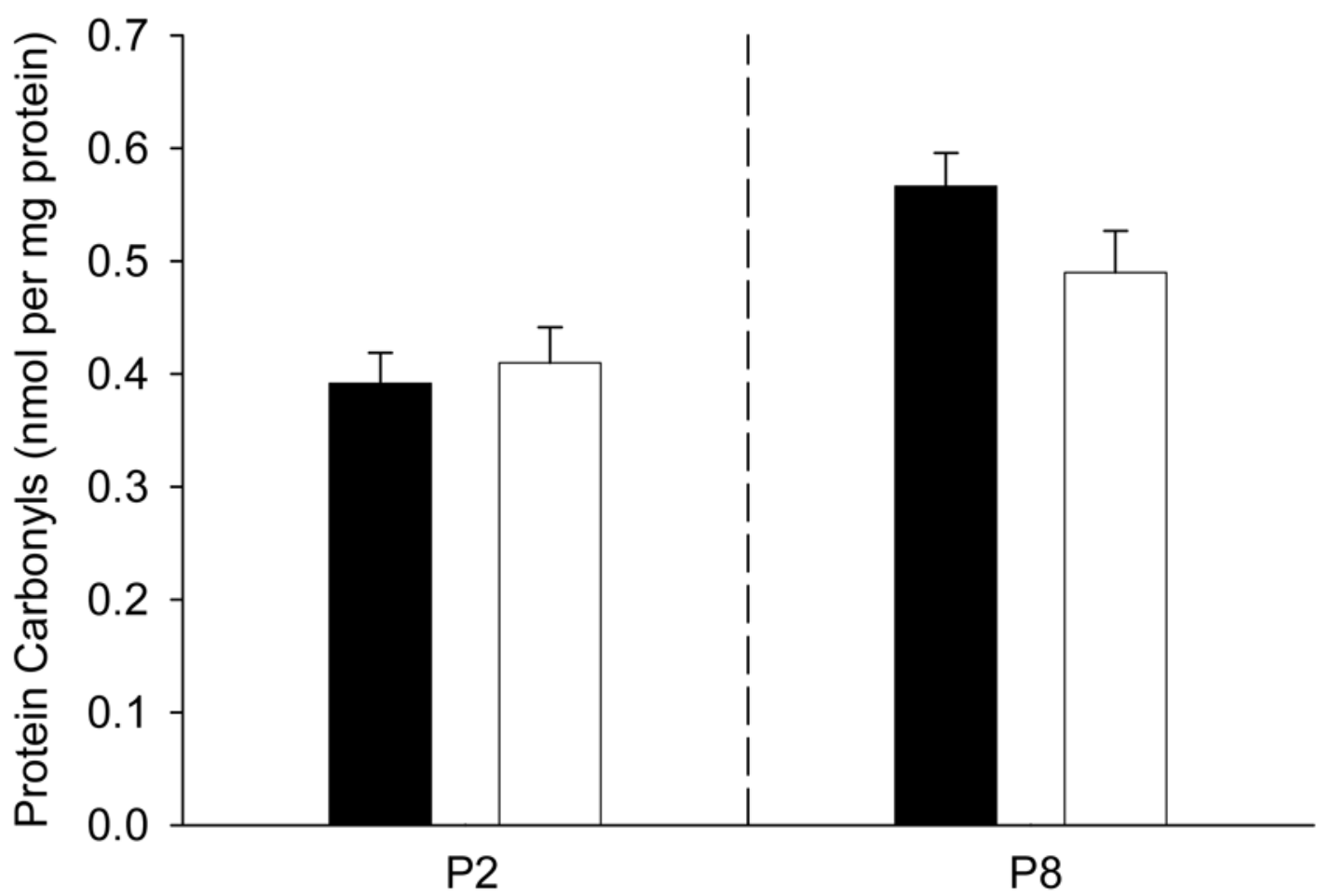

Fig. 5.

Protein carbonyl concentrations in blood plasma of two-day-old (P2) and eight-day-old (P8) rats raised from birth in $21 \% \mathrm{O}_{2}$ (Normoxia) or $60 \% \mathrm{O}_{2}$ (Hyperoxia). Values are means \pm S.E.M.; $\mathrm{n}=7$ per group, except $\mathrm{n}=6$ for Normoxia at $\mathrm{P} 2$. No effect of hyperoxic exposure was detected at either age (both $P>0.05$ ). 


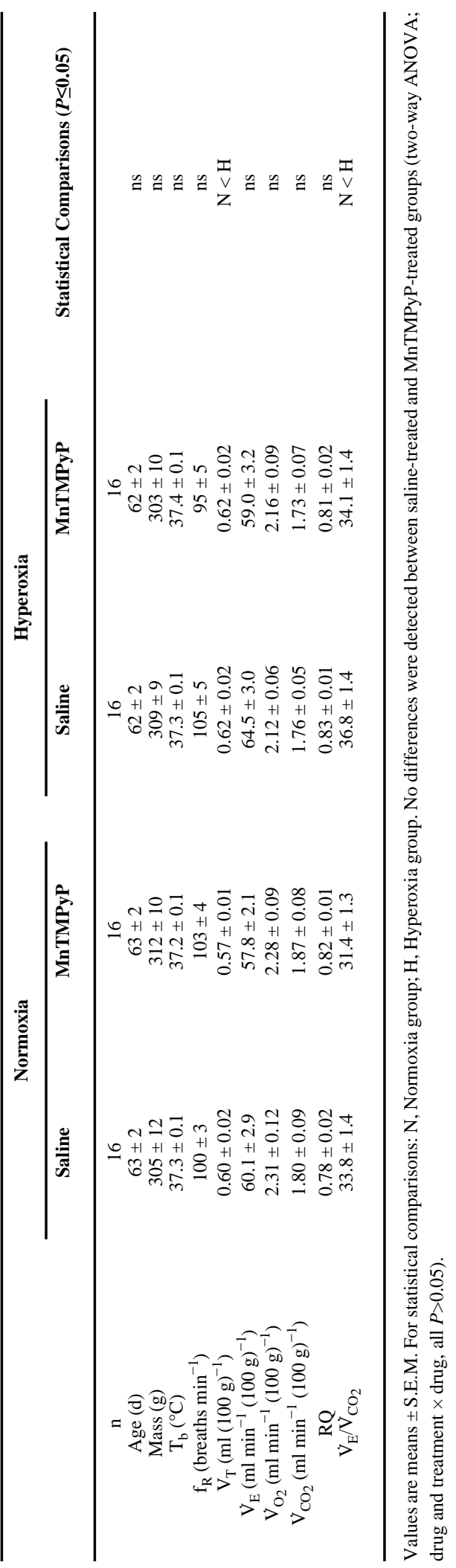

